\title{
COVID-19 Pandemisinde Sağlık Hizmetlerine Erişim: Çocuk Sağlığı Nasıl Etkilendi?
}

\section{Access to Health Care in the COVID-19 Pandemic: How is Children's Health Affected?}

\section{Zeynep Aközlü ${ }^{10}$, Özlem Öztürk Şahin² ${ }^{(0)}$}

${ }^{1}$ Maltepe Üniversitesi, Meslek Yüksekokulu Tıbbi Hizmetler ve Teknikler Bölümü, İstanbul, Türkiye

${ }^{2}$ Karabük Üniversitesi, Sağlık Bilimleri Fakültesi Hemşirelik Bölümü, Çocuk Sağlığı ve Hastalıkları Hemşireliği Anabilim Dalı, Karabük, Türkiye

ORCID ID: Z.A. 0000-0003-4561-4025; 0̈.ö.Ş. 0000-0001-8781-3706

Citation/Atıf: Akozlu Z, Ozturk Sahin O. COVID-19 pandemisinde sağlık hizmetlerine erişim: Çocuk sağlığı nasıl etkilendi? Çocuk Dergisi - Journal of Child 2021;21(2):149-156. https://doi.org/10.26650/jchild.2021.953569

ÖZ

COVID-19, Dünya Sağlık Örgütü tarafından 11 Mart 2020 tarihinde pandemi olarak ilan edilmiştir. Hastalığın yüksek bulaşıcılığı nedeniyle tüm dünyada sağlık hizmetleri sunumunda değişikliklere gidilmiş, sağlık otoriteleri acil nedenler dışında hastane başvurularının azaltılması çağrıları yapmıştır. Viral yayılımı önlemek için uygulanan kısıtlamalar, hastalığın belirsizliğine ilişkin korkular, sağlık profesyonellerinin enfekte hastaların takibi, tedavisi ve bakımına yönlendirilmesi, kişisel koruyucu ekipman eksikliği ve pandeminin getirdiği finansal zorluklar nedeniyle COVID-19 dışı sağlık hizmetlerine erişim oranlarında keskin bir düşüş yaşanmıştır. COVID-19'un neden olduğu bu durumdan en çok etkilenen popülasyon şüphesiz ki çocuklar olmuştur. Sağlık hizmeti sunumundaki değişiklikler nedeniyle ana-çocuk sağlığı hizmetleri sekteye uğramış, bağışıklama oranları büyük ölçüde azalmıştır. Enfekte hastalara müdahale edebilmek için polikliniklerin kapatılması, yataklı servisler ve ameliyathanelerin yoğun bakımlara dönüştürülmesi çocukların akut veya kronik hastalıklarının tanı ve tedavilerinde gecikmelere neden olmuştur. Kronik hastalığı olan çocuklar ilaç veya tıbbi ekipman sıkıntısı yaşamış, rehabilitasyon hizmetlerine ihtiyaç duyan çocuklar destekleyici bakım alamamışlardır. Ayrıca okulların kapatıımasıyla koruyucu ruh sağlığı hizmetleri sürdürülememiştir. Sağlık hizmetlerine erişim oranlarındaki azalmalar, başta düşük ve orta gelirli ülkeler olmak üzere tüm dünyada çocukluk çağı mortalite ve morbiditesi üzerinde olumsuz sonuçlar doğurabilir. Türkiye'de çocuk sağlığına yönelik kazanımların sürdürülmesi ve sağlık hizmetlerinin planlanması açısından dünyadaki verilerin incelenmesi önemlidir. Dolayısıyla bu derlemede, küresel salgın sürecinde sağlık hizmetlerine erişimdeki azalmanın çocuk sağlığı üzerindeki etkilerinin incelenmesi amaçlanmıştır.

Anahtar Kelimeler: COVID-19, çocuk, sağlık hizmetlerine erişim, pandemi
ABSTRACT

COVID-19 was declared a pandemic by the World Health Organization on March 11, 2020. Due to the high contagiousness of the disease, changes have been made in the provision of health services all over the world, and health authorities have made calls to reduce hospital admissions except for urgent reasons. Access to non-COVID-19 healthcare services has declined sharply due to the restrictions imposed to prevent viral spread, fears about the uncertainty of the disease, the redirection of healthcare professionals to the follow-up, treatment and care of infected patients, the lack of personal protective equipment, and the financial difficulties brought on by the pandemic. The population most affected by this situation caused by COVID-19 has undoubtedly been children. Due to changes in health service delivery, maternal and child health services have been interrupted, and immunization rates have decreased greatly. The closure of outpatient clinics, inpatient services and the conversion of operating rooms to intensive care units in order to intervene with infected patients have caused delays in the diagnosis and treatment of acute or chronic diseases in children. Children with chronic diseases experienced shortages of drugs or medical equipment, and children who needed rehabilitation services could not receive supportive care. In addition, preventive mental health services could not be maintained with the closure of schools. Decreases in access to health services may have negative consequences on childhood mortality and morbidity all over the world, especially in low and middle-income countries. It is important to examine the data in the world in terms of maintaining the achievements for child health and planning health services in Turkey. Therefore, this review aimed to examine the effects of the decrease in access to health services on child health during the global epidemic process.

Keywords: COVID-19, child, health care access, pandemic

Sorumlu Yazar/Corresponding Author: Özlem Öztürk Şahin E-mail: ozlem.ozturk@karabuk.edu.tr

Başvuru/Submitted: 16.06.2021 • Revizyon Talebi/Revision Requested: 30.06.2021 • Son Revizyon/Last Revision Received: 02.07.2021 • Kabul/Accepted: 13.07.2021 


\section{GíRiş}

Sağlık hizmetlerine erişim temel bir insan hakkıdır, ancak tüm dünyada COVID-19 pandemisinin sağlık sistemleri üzerine uyguladığı yük, birçok insanın sağlık hizmetlerine erişimini etkilemiştir (1). COVID-19'un pandemi olarak ilan edilmesinden itibaren, yüksek bulaşma riski nedeniyle, acil nedenler dışında hastanelere ve acil servislere ziyaretler önerilmemiştir (2). Hastaneler, enfekte hastalarla ilgilenmek ve salgın yönetimini sürdürebilmek amacıyla organizasyonel değişikliklere gitmiştir (3). COVID-19, sağlık hizmetleri için benzeri görülmemiş zorluklar doğurmakla birlikte pediatrik popülasyonun sağlık hizmetlerini kullanım düzeninde değişikliklere yol açmıştır (4). Birçok pediatrik sağlık hizmeti sunan kurum, durumu kritik olan hasta yetişkinleri tedavi etmek için yataklı servislerini dönüşüme uğratmış ve yatan hasta kabullerini veya ameliyatları hayatı tehdit eden koşullarla sınırlamıştır (5).

COVID-19'un sağlık hizmeti sunumu üzerindeki etkilerinin, özellikle sağlık sistemlerinin zaten kırılgan olduğu düşük orta gelirli ülkelerde daha da derin olması beklenmektedir (6-8). Çünkü hükümetler çocuk sağlığı ihtiyaçları için zaten yetersiz olan sağlık bütçelerini, COVID-19 salgınını yönetmeye ayırmak durumunda kalmıştır (8). Ayrıca ebeveynlerin hastanelerde $(9,10)$ veya toplu taşıma araçlarında enfekte olma korkuları, ulaşım hizmeti kesintileri ve kapanmalar nedeniyle birinci basamak sağlık hizmetlerine erişememesi, ebeveynlerin çocuklarını hastanede yalnız bırakmak zorunda kalacakları hastane ziyaret politikaların olması (11) ve salgının ebeveynlere getirdiği ekonomik zorluklar (12) çocukların pandemi sürecinde sağlık hizmetlerine erişimi önünde engel oluşturmuştur. Bu derlemede, küresel salgın sürecinde sağlık hizmetlerine erişimdeki azalmanın çocuk sağıı̆ı üzerindeki etkilerinin incelenmesi amaçlanmıştır.

\section{KLINIK VE ARAŞTIRMA ETKILERI}

\section{TEMEL/KORUYUCU SAĞLIK HIZMETLERI}

\section{Ana-Çocuk Sağlığı Hizmetleri}

COVID-19 pandemisi, ülkelerin yüksek kaliteli temel ana-çocuk sağlığı hizmetlerini sürdürmelerini engelleyen önemli zorlukları beraberinde getirmiştir. Ülkelerin nitelikli sağlık personeli kaynakları, düzenli temel sağlık hizmeti sunumundan pandemi ile müdahale çabalarına yönlendirilmiştir. Ayrıca gebeler ve yenidoğanları olan anneler, ulaşım kısıtlamaları ve kapanma önlemleri nedeniyle temel sağıı hizmetlerine erişimde zorluk çekmiş veya enfeksiyon korkusu nedeniyle sağlık kuruluşlarına gitme konusunda isteksiz olmuşlardır (13). Nijerya'da 22 farklı sağlık merkezinde yapılan bir çalışmada kadınların \%43,51'inin COVID-19 salgınından bu yana ana-çocuk sağlığı hizmetlerine erişimde en az bir zorluk yaşadığı ve \%18,13'ünün ulaşım olmadığı için hizmete erişemediği saptanmıştır (14). Sağlık kuruluşlarına ulaşmayı başaran annelerin de zamanında bakım almadıklarına yönelik endişeler vardır (15). Çin'de pandemi nedeniyle gebelerin yarısından fazlası doğum öncesi bakım ziyaretlerini ertelemiş veya iptal etmiştir (16). Doğum öncesi bakım alma oranının Nijerya'da \%85, Bangladeş'de \%56,9, Güney Afrika'da da \%28,6 oranında azaldığı görülmüştür (17).
Pakistan'da maternal tetanoz aşılarının \%28,8 oranında daha az uygulandığı saptanmıştır (18). Düşük ve orta gelirli 118 ülke ile yapılan bir modelleme çalışmasında, pandemi nedeniyle ana sağlığı hizmetlerine erişim engellerinin anne ölümlerini $\% 8,3$ ile \%38,6 arasında değişen oranlarda arttrabileceği ve bu hizmetlere erişimdeki \%15'lik bir azalmanın 250.000'den fazla ek ölümle sonuçlanabileceği saptanmıştır (12). Uganda'da yapılan çalışmada pandemi döneminde artan abortuslar, sezaryen doğumlar, kanamalar, preterm ve düşük doğum ağırlıklı bebekler ile yenidoğan resüsitasyonu sayılarındaki artışın, doğum öncesi bakım hizmetlerine yapılan başvuruların azalmasıyla ilişkili olduğu gösterilmiştir (19).

Bir kadının bebeğini doğurması için en güvenli yer, nitelikli bir sağlık profesyoneli ile fonksiyonel bir sağlık kuruluşudur. Bu küresel kriz sırasında, birçok kadının nitelikli destek olmadan evde doğum yapabileceğine ilişkin endişeler belirtilmektedir (13). Özellikle düşük ve orta gelir düzeyli ülkelerde yapılan çalışmalarda bu endişeye yer verilmiştir $(17,20)$. Ancak gelişmiş ülkelerde bile annelerin pandemi nedeniyle evde doğum yapma isteklerinin arttığı görülmüştür (21). Mozambik'te evde gerçekleşen doğumların 2019 yılında göre \%74 artış gösterdiği saptanmıştır (22). Yaşamın ilk günlerinde yenidoğanların savunmasızlığı göz önüne alındığında, anneler ve bebekleri için doğum sonrası bakım hizmetlerine öncelik verilmesi de hayati önem taşır. Bu kurtarıcı müdahaleler bozulursa, daha birçok anne ve yenidoğan tedavi edilebilir ve önlenebilir koşullardan hayatını kaybedebilir (13). Uganda'da doğum sonrası bakım alan anne ve yenidoğanların sayısının \%11, anne sütü ile beslenen yenidoğanların $\% 8$ oranında azaldığı saptanmıştı (19). Anne sağlığının çocuk sağlığı üzerinde doğrudan bir etkisi bulunduğundan, anneye yönelik koruyucu hizmetlerin pandemi varlığında da sürdürülebilmesi çok önemlidir. UNICEF (2021), COVID-19 şüphesi veya varlığında bile tüm gebelerin, hem kendileri hem de bebekleri için nitelikli bir sağlık personelinden sağlık hizmeti almaya devam etmelerinin önemini vurgulamaktadır. Ayrıca devletlerin de bu hizmetin devamlıı̆ı̆ı sağlayabilmesi için gerekli yatırımları yapmalarının önemli olduğunun altını çizmektedir.

Uluslararası Pediatri Birliği (International Pediatric AssociationIPA), pandemi sırasında çocuk sağlığına yönelik birinci basamak hizmetlerin sürdürülmesinin önemini vurgulamaktadır (23). Roberton ve ark. (2020) ana çocuk sağlığı hizmetlerinin kullanımındaki bozulmanın 5 yaş altı ölüm oranlarını \%9,8 ile $\% 44,7$ oranında arttırabileceğini ortaya koymuştur. Güney Afrika'da 11 farklı birinci basamak sağlık merkezinde yapılan çalışmada 5 yaş alt çocuk sağlığı izlemlerinde \%50'den fazla oranda azalma saptanmıştır (24). İtalya'da yenidoğanların beslenme ile ilgili problemler nedeniyle acil servise başvuru oranlarının \%56,4'ten \%81,4'e yükseldiği rapor edilmiştir. Bu sonuç, kapanma önlemleri nedeniyle çocuk sağlığı izlemlerinin yapıldığı birinci basamak sağlık hizmetlerine sınırlı erişimle ilişkilendirilmiştir (2). Türkiye'de bir aile sağlığı merkezinde yürütülen çalışmada, pandemi süresince gebe ve bebeklerin rutin takip zamanları gelince aile sağlığı merkezine çağrılarak, izlemlerinin yapılmaya devam edildiği, izlemlerde herhangi bir aksama yaşanmadığı ve izlem sayısında herhangi bir eksiklik olmadığı ifade edilmiştir (25). 


\section{Bağışıklama}

Aşılar halk sağlığı tarihindeki en önemli girişimlerden biridir ancak pandemi bu kazanımları riske atmıştır (26). Çok sayıda ülke şu anda çocukluk çağı bağışıklama oranlarında hızlı bir düşüş yaşamaktadır (27). DSÖ, 68 düşük gelirli ülkede rutin çocukluk aşılama hizmetlerinin askıya alındığını veya ertelendiğini ve ülkelerin aşı tedariki eksikliği nedeniyle 1 yaşın altındaki 80 milyondan fazla çocuğun etkilendiğini bildirmiştir (28). Pakistan'da çocuk felcinin ortadan kaldırılmasına yönelik hizmetlerde çalışan 6260 sağlık profesyonelinin filyasyona yönlendirilmesi ve pandemi nedeniyle getirilen sokağa çıkma kısıtlamaları nedeniyle 2 yaş alt çocukların aşılama oranlarında \%51 azalma kaydedilmiştir (18). Pakistan'da yapılan bir diğer çalışmada sadece bir ay içerisinde yaklaşık 40 milyon çocuğun çocuk felci aşılarını pandemi nedeniyle kaçırdığı saptanmıştır (29). Uganda'da tek merkezli bir çalışmada yaklaşık 20.000 çocuğun aşıyla önlenebilir hastalıklar açısından ölüm riski altında olduğu rapor edilmiştir (19). Teksas'ta yapılan bir çalışma kırsal alanlardaki 5 aylık çocukların, kentsel alanlardaki 5 aylık çocuklardan daha fazla bağışıklama hizmeti kesintisi yaşadığını göstermiştir (30). Endonezyalı ebeveynlerin \%13,3’ü pandemi nedeniyle çocuklarının hiç aşılanamadığını, \%27,4'ü ise çocuklarının zorunlu aşılarını ertelemek zorunda kaldığını ifade etmiştir. Ayrıca ebeveynlerin finansal zorlukları arttıça çocuklarının zorunlu aşılarını geciktirme olasılığının daha yüksek olduğu saptanmıştı (31). Kanadalı ebeveynler pandemi sırasında çocuklarına aşı yaptırmalarının önündeki engellerin \%77,8 oranında kişisel koruyucu ekipman eksikliği ve \%31,3 oranında enfeksiyonla ilgili kaygıları olduğunu ifade etmişlerdir (32). Singapur'da yapılan bir araştırmada üç tür sağlık biriminde (kamu birinci basamak, hastane pediatri ünitesi ve özel çocuk doktoru klinikleri) çocukluk çağı Kızamık-KızamıkçıkKabakulak (KKK) aşılarının uygulanma oranları geçmiş yıllarla kıyaslanmış ve \%25,6 ile \%73,6 arasında değişen bir oranda azalma olduğu saptanmıştır. Bu sonuçların toplum bağışıklığı için gerekli olan \%95 aşılanma hedefini tehlikeye soktuğu ve kızamık salgını için risk oluşturduğu ifade edilmiştir $(18,33)$. Bağışıklama hizmetlerinde herhangi bir bozulma, kısa bir süre için bile olsa, aşı ile önlenebilir enfeksiyonların artmasına ve aşı ile önlenebilir hastalıklara bağlı çocukluk çağı morbidite ve mortalitesine ciddi olumsuz etkilerde bulunabilir $(18,34)$. DSÖ, COVID-19 pandemisi sırasında tüm rutin aşıların planlandığı gibi uygulanmasını önermektedir. Rutin bağışıklama programları, mümkün olduğunca özel önlemler kullanılarak devam etmelidir (35). Herhangi bir kesintiye uğrama durumunda aşılama hizmetleri mümkün olduğunca çabuk sunulmalı ve kaçırılmış aşılar tamamlanmalıdır (36).

\section{Koruyucu Ruh Sağlığı Hizmetleri}

Kritik bir gelişim döneminde olduklarından, çocukların ruh sağlığının geliştirilmesi ve korunması için özel bir ilgiye ihtiyaçları vardır (37). Ruh sağı̆̆ındaki bozulmaların çoğu çocuklukta başlar ve bu da ruhsal sağıık intiyaçlarının olabildiğince erken tespit ve tedavi edilmesini gerekli kılar (38). Okullar, çocuklar için hem bir sosyal destek ağı hem de koruyucu ruh sağlığı hizmeti sunan en önemli kurumlardandır. Nisan 2020 itibariyle, 188 ülkede okullar kapatımıştır. Bu, okul çağındaki çocukların \%90'ından fazlasının okullarından uzakta olduğu anlamına gelmektedir (39). COVID-19 pandemisi sırasında okulların kapatılması, okul temelli koruyucu ruh sağlığı hizmetlerini sekteye uğratmıştır (40). Koruyucu ruh sağlığı hizmetlerini sürdürebilmek pandemi döneminde daha da önemli hale gelmiştir. Literatür, COVID-19'un çocuklar üzerinde acil eylem gerektiren ve uzun vadeli ruhsal sağlık etkileri olabileceğini göstermektedir (41-44).

\section{TEDAVI EDICI SAĞLIK HIZMETLERi}

\section{Acil Başvuruları}

COVID-19 acil durumunun ilk günlerinden itibaren, yüksek bulaşma riski nedeniyle, acil nedenler dışında hastanelere ve acil servislere ziyaretler önerilmemiştir (2). COVID-19, pediatrik popülasyonda genellikle kötü olmayan bir prognoz ve düşük ölüm oranı sunarak önemli bir tehdit oluşturmuyor gibi görünse de, mevcut acil durum pediatrik hastaların bakımını ve genel çocuk refahını olumsuz yönde etkileyebilir. Özellikle, enfeksiyona yakalanma korkusu, pediatrik acil servislere gecikmeli erişimi tetikleyebilir (45). Pandemi ile ilişkili yaşam tarzı değişiklikleri ve kısıtlamalar, pediatrik acil servise kabullerde bir azalmaya ve yoğun bakım gereksiniminde bir artş̧a neden olmuştur (46). Acil servis başvurularında azalma ve ertelenmiş bakım ile artan morbidite arasındaki ilişki göz önüne alındığında, hastane başvurusu ertelenen çocuklar normalden daha yüksek ciddiyetle hastaneye kabul edilmektedir $(47,48)$.

Amerika Birleşik Devletleri (ABD)'de genel popülasyon üzerinde yapılan çalışmada tüm yaş grupları arasında acil servis başvurularının en fazla pediatrik popülasyonda azaldığı ve bu azalmanın 0-2 yaş arasında \%62 ve 3-14 yaş arasında \%44 olduğu saptanmıştır (47). İtalya'da yapılan çalışmada ise 5 günlük süre içerisinde 5 farklı pediatrik hastanede 12 gecikmeli olgu saptanmış ve 12 ebeveyn de enfeksiyondan korktuğu için hastaneye gitmediğini bildirmiştir. Bu olgular içerisinden 5 aile, acil servise erişmeden önce sağlık hizmetleri ile temasa geçmiş, ancak enfeksiyon riski nedeniyle hastaneye erişim önerilmediğini ifade etmiştir. Çalışmada 6 çocuğun yoğun bakım ünitesine kabul edildiği ve 4'ünün hayatını kaybettiği saptanmıştır (10). İtalya'da yapılan bir diğer çalışmada gecikmiş erişim nedeniyle büyük ölçüde kötüleşen dört pediatrik hasta rapor edilmiştir. Ebeveynlerin COVID-19'a yakalanma korkusu nedeniyle, çocuklar olması gerekenden daha uzun süre evde tutulmuş ve 4 çocuktan 2'si yoğun bakım ünitesine kabul edilmiştir (45). Hindistan'da pediatrik acil servis başvurularında \%65 düşüş ve \%10,4 daha fazla yoğun bakım gereksinimi saptanmıştır (46).

Acil servisler, çocuğa yönelik kötü muamele olgularının tespit edilebileceği öncelikli birimlerdendir (49). Şu anda tüm dünyada halk sağlığı önlemi olarak kullanılan sosyal izolasyon, çocuğa yönelik kötü muamele için önemli bir risk faktörüdür (50). Okulların kapatılması ve çocukların öğretmenlerinden uzak kalması da çocuğa yönelik kötü muameleye ilişkin bulguların erken saptanması önündeki engellerden biridir (51). Ayrıca acil durumların ve doğal afetlerin, çocuk koruma hizmetlerini zayıflatthğı ve önleyici tedbirleri bozduğu için çocuğa yönelik kötü muamele riskini arttırdığı bilinmektedir. Bu nedenle 
pandemi nedeniyle acil servislere yapılan başvurulardaki azalmanın çocuğa yönelik kötü muamele olgularının tespitinde önemli bir engel olduğu da unutulmamalıdır (52). ABD'de yapılan bir araştırma, okulların kapanmasından sonraki ilk iki ayda çocuğa yönelik kötü muamele ile ilgili başvuruların sayısında \%27'lik bir azalma olduğunu rapor etmiştir (53).

\section{Poliklinik Hizmetleri}

COVID-19 vakaları artthç̧a ve hükümetler evde kalma tedbirleri uyguladıkça tedavi nedeniyle hastaneye yapılan başvurular önemli ölçüde azalmıştır (54). Portekiz'de 19.745 çocuk üzerinde yapılan çalışmada önceden planlanmış ayaktan tedavi randevularının \%54,2'sinin sağlık kurumları tarafindan ertelendiği saptanmıştır (4). ABD'de yapılan çalışmada salgın sırasında bakım vericilerin \%26'sı gecikmiş/iptal edilmiş pediatrik onkoloji randevusu, \%19'u gecikmiş/iptal edilmiş görüntüleme hizmeti rapor etmiştir. Ayrıca bakım vericilerin \%9'u da randevulara ulaşım zorlukları bildirmiştir (55). Benzer şekilde lösemili çocuk anneleriyle yapılan bir çalışmada annelerin çocuklarına enfeksiyon taşımamak için işlerini bıraktı̆ı ve bunun da ekonomik zorluklara neden olduğu, bundan dolayı da çocuğunu hastaneye götürmekte (araç bulma vb.) zorlandığı saptanmıştır (56). Tüm kıtalardan 212 çocuk nöroloğuyla yapılan bir çalışmada COVID-19'un bir sonucu olarak, yüz yüze muayenelerde $\% 91,5$, elektroensefalogram (EEG) ile yapılması gereken tanısal işlemlerde $\% 90,6$ oranında bir azalma olduğu bildirilmiştir. Çocuk nörologlarının \%54,1'i epilepsi tanısı koyabilmek için ebeveynlerin gönderdiği videolara güvenmek durumunda kaldığını beyan etmiştir. Yazarlar EEG olmadan tanı koymanın, optimal olmayan tedavi stratejilerine ve çocuklarda potansiyel olarak olumsuz sonuçlarda artş̧a neden olabileceğinin altını çizmişlerdir (5).

\section{Kronik Hastalıkların Takibi ve Tedavisi}

Uluslararası Çocuk ve Ergen Diyabet Derneği (International Society for Pediatric and Adolescent Diabetes-ISPAD)'nin, COVID-19 pandemisi sırasında dünya çapında diyabetli çocuklara ve adölesanlara bakım veren sağlık profesyonellerinin algılarını, zorluklarını ve deneyimlerini araştırdığı çalışmaya 75 ülkeden toplam 215 diyabet merkezi katılmıştır. Merkezlerin yalnızca \%16,5'inin uygun kişisel koruyucu ekipmanla diyabetli çocuklarla yüz yüze konsültasyona devam edebildiği belirlenmiştir. Merkezlerin \%22'si yeni başlangıçlı diyabetli hastaların tanısında gecikme ve $\% 15^{\prime} i$ daha yüksek diyabetik ketoasidoz insidansı bildirmiştir. Ayrıca takip altındaki çocukların \%19'unun kan şekeri sensörü, insülin ve keton stribi gibi malzemelerin temini konusunda problem yaşadığı görülmüştür (57). Ürdün'de diyabetli çocukların ebeveynleriyle yapılan çalışmada, ebeveynlerin \%58.3'ünün insülin temin etmekte güçlük yaşadığı saptanmıştır. Aileler insülin temini önündeki engellerin sokağa çıkma yasakları nedeniyle hastaneye ulaşamama $(\% 56,9)$, insülin sağlayan tıbbi kurumun hasta kabul etmemesi $(\% 42,3)$, insülin satın almanın pahalı olması $(\% 40,9)$ ve enfeksiyona maruz kalma korkusu $(\% 35,0)$ olduğunu bildirmişlerdir. Ailelerin çocuklarının insülin kullanımını kısıtlaması nedeniyle, çocukların \%54,5'inin hiperglisemi yaşadığı saptanmıştır. Ailelerin $\% 74,5^{\prime}$ i normalden daha fazla glikoz stribi satın alması gerektiğini, \%43,4'ü çocuklarının glikoz stribini kullanımını kısıtladığını ve buna bağlı olarak çocuklarının \%75,5 oranında daha sık hipoglisemik veya hiperglisemik sonuçlarla karşılaştı̆̆ını rapor etmişlerdir (58).

79 ülkeden 213 farklı pediatrik hematoloji-onkoloji hizmeti sunan kurumda yürütülen çalışmada, merkezlerin \%78'i, pandeminin kanserli çocuklara bakım sağlama kapasitesi üzerinde bir etkisi olduğunu, kanser tedavisinde ve hasta desteğinde (hastalar ve aileler için psikolojik, sosyal, finansal destek ve eğitim) aksamalar ve klinik personel eksikliğinin en sık belirtilen etkiler olduğunu bildirmiştir. Hastanelerin \%7'si kliniklerin tamamen kapandığını beyan etmiştir (\%87'yi düşük ve orta gelirli ülkeden hastane) ve ortalama kapanma süresi 10 gün (en az 1, en fazla 75 gün) olarak saptanmıştır. Kurumların \%2'si yeni şüpheli kanser vakalarını değerlendiremezken, merkezlerin \%43'ü yeni teşhis edilen pediatrik kanser vakalarında bir azalma olduğunu rapor etmiştir. Kurumların \%34'ü kanser tedavilerini hiç başlatamamış veya 4 haftadan uzun süre ertelemiştir. Kemoterapi yönetiminde değişiklikleri tanımlayan 121 kurum arasından 84'ü (\%69) doz yoğunluğunda bir azalma, 59'u (\%49) intravenözden oral formülasyona geçiş ve $25^{\prime} i$ (\%21) kemoterapinin tamamen kesildiğini bildirmiştir. Tüm kurumların \%60'ında depolardaki mevcut kan ve kan ürünü sayısının yetersiz olduğu ve sadece $\% 20$ 'sinin acil radyoterapi uygulayabildiği saptanmıştır. Ayrıca kurumların \%66'sında klinik personel sayısında azalma olduğu ve bunun en sık nedeninin $\% 60$ oranında personelin enfekte olma durumu ile ilişkili olduğu görülmüştür. Aynı çalışmada kurumların \%50'sinde klinik personelin kişisel koruyucu ekipmanının yetersiz olduğu saptanmıştır (59).

ABD'de 29 farklı merkezle yürütülen bir çalışmada merkezlerin \%72'si parenteral nutrisyona bağımlı bağırsak yetmezliği olan çocukların pandemiden etkilendiğini bildirmiştir. Merkezlerin \%52'si çocukların parenteral nutrisyon reçetesinde değişiklik yapma konusunda isteksizlik yaşamışlardır ve yazarlar bunun nedeninin çocukların antropometrik ölçümlerinin yapılmaması ile ilişkili olabileceğini öne sürmüşlerdir. Ailelerin \%28'inin infüzyon kateteri ve line bakımı ile ilgili zorluklar yaşadığı ve merkezlerin ailelere malzeme tedariki sağlayamaması nedeniyle maske ve eldiven gibi bazı ürünleri tekrar kullanmalarını söylemek zorunda kalması da çalışmada saptanan bulgulardır. Ayrıca merkezler ailelerin ateş, beslenme intoleransı veya kanlı dışkılama durumlarında bile hastaneye erişmekten çekindiğini bildirmişlerdir (60).

\section{Cerrahi Operasyonlar}

Bir halk sağlığı krizi sırasında bakıma erişim güçlükleri, çocukların cerrahi durumlar için hızlı bir değerlendirme almasını engelleyebilir (61). COVID-19, pediatrik cerrahi hizmetlere erişim üzerinde de önemli bir etki göstermiştir. Dünyanın pek çok yerindeki cerrahi departmanlar, acil olmayan tüm prosedürleri durdurmuştur. Cerrahi hastalıkların tanı ve tedavisindeki gecikmeler, en savunmasız nüfus olan çocuklar arasında önemli mortalite ve morbidite oranları ile sonuçlanabilir (1).

Epilepsi cerrahisi değerlendirmelerinde ve rezeksiyonlarındaki 
gecikmeler, çocukların onarılamaz nörogelişimsel hasarlar yaşamalarını ve mortalite olasılığını artırmaktadır. Cerrahi olarak tedavi edilebilen yapısal beyin anormalliği nedeniyle sık sık devam eden nöbetleri olan çocuklarda, gecikmiş cerrahinin zararları COVID-19 riskinden daha kötü olabilir. Epilepsi cerrahisi üzerine yapılan bir çalışmada, cerrahların yarısından fazlası cerrahi öncesi değerlendirme için herhangi bir çocuğu kabul edememiş ve üçte birinden fazlası tüm epilepsi ameliyatlarının COVID-19 nedeniyle beklemede olduğunu beyan etmiştir. Geri kalan cerrahlar ise ameliyatların sadece yaşamı tehdit eden vakalarla sınırlı olduğunu bildirmişlerdir (5).

Akut apandisit, çocuklarda abdominal cerrahi için en yaygın endikasyonlardandır ve apandisitin perforasyona ilerlemesi, hastaneye kabul zamanlamasından etkilenir. COVID-19 salgını sırasında, birçok ebeveyn, enfekte olma korkuları nedeniyle çocuklarının karın ağrısı şikayetlerine yönelik yaptıkları acil başvurularını geciktirmiştir. ABD'de 3 farklı hastanede yürütülen çalışmada, önceki 5 yıla kıyasla \%18 daha fazla perfore apandisit olgusu saptanmıştır. Ayrıca bu nedenle çocukların hastanede kalış süresi de artı̧ göstermiştir (61).

Pediatrik hematoloji-onkoloji hizmeti sunan hastanelerle yapılan çalışmada kurumların \%72'si pediatrik onkoloji hastalarının cerrahi hizmetleri kullanabilirliğinin azaldığını ve $\% 6^{\prime}$ sı cerrahi prosedürlerin tamamen kesildiğini rapor etmiştir (59). Ülkemizde Şanlıurfa'da yapılan bir çalışmada ise pandemi öncesinde pediatrik üroloji ameliyatı sayısı 741 iken, pandemi sırasında bu sayının 316 olduğu ve pediatrik üroloji ameliyatlarında \%58,4 azalma olduğu saptanmıştır (62).

\section{Tedavi Edici Ruh Sağlığı Hizmetleri}

COVID-19 nedeniyle çocuk ve ergen psikiyatrisi hizmetleri de askıya alınmak durumunda kalınmıştır (63). Hâlihazırda ruhsal sağıık sorunları olan çocuklar, pandemi nedeniyle yüksek risk altındadır. Çoğu ruhsal bozukluk düzenli psikoterapi ve psikiyatrik tedavi gerektirir. Sağlık hizmetlerine erişim eksikliği nedeniyle ruhsal bozuklukların şiddeti ve sonuçları kötüleşebilir (64). Pandemi ile birlikte tele-ruh sağlığı hizmetleri ön plana çıksa da, gizlilik, güvenlik ve finansal eşitsizlikler nedeniyle bu hizmetin çocuklarda kullanımının elverişli olmadığı ifade edilmiştir (65). Türkiye'de 6-12 yaş arası çocukların pandemi nedeniyle karşılanmamış sağlık ihtiyaçlarının incelendiği çalışmada, çocukların \%12,8'inin ruh sağlığı ile ilgili desteğe ihtiyaç duyduğu halde sağlık hizmeti alamadığı belirlenmiştir. Ebeveynler bunun enfekte olmaktan korkma nedeniyle olduğunu ifade etmiştir (66). İngiltere'de psikiyatrik öyküsü olan 2111 katılımcıyı içeren çalışmada, çocuk ve ergenlerin \%83'ü pandeminin ruhsal koşullarını daha da kötüleştirdiğini ve \%26'sı ruh sağlığı desteğine erişemediklerini, akran destek gruplarının ve yüz yüze hizmetlerin iptal edildiğini bildirmiştir (67). Kanada'da COVID-19'un dikkat eksikliği ve hiperaktivite bozukluğu olan çocuklara etkilerinin incelendiği çalışmada ise bakım vericilerin üçte biri çocukların pandemi sırasında terapiye ve ilaç dozu düzenlemesine erişimde güçlükler olduğunu ifade etmiş ve onda biri, çocuklarına reçete edilen ilaçları almakta güçlük çektiğini bildirmiştir (68).

\section{REHABILITE EDICI SAĞLIK HIZMETLERi}

Engelli çocuklar, fonksiyonel sınırlamaları ve kırılganlıklarının bir sonucu olarak, uzun süreli tedaviler ve hastane dışında özel destek gerektiren durumlarla karşı karşıyadır. Bu nüfusun karantina veya izolasyon sırasında da sağlık hizmetlerine erişimlerini sürdürmeleri gerekir (3). Pandeminin yayılmasını engellemek amacıyla uygulanan önlemler nedeniyle, rehabilitasyon hizmetlerine ihtiyaç duyan çocuklara onları tehlikeye atabilecek bir hastane ya da terapi ortamını ziyaret etmek yerine evde kalmaları önerilmiştir (69).

COVID-19 kısıtlamaları sırasında zihinsel ve gelişimsel engelli çocukların eğitim ve sağlık hizmetlerine erişimlerinin incelendiği çalışmada $A B D$ ve 28 farklı ülkeden veriler incelenmiştir. ABD'de yaşayan bakım vericilerin \%74'ü ve ABD dışındaki bakım vericilerin \%78'i çocuklarının en az bir terapi (konuşma terapisi, ergoterapi, fizyoterapi vb.) veya eğitim hizmeti almadığını bildirmiştir. Terapi ve eğitim hizmetlerini hiçbir şekilde alamayan çocuklarınsa $A B D$ 'de $\% 30$ ve $A B D$ dışındaki ülkelerde $\% 50$ olduğu saptanmıştır. Aynı çalışmada hem ABD'de hem de diğer ülkelerde yaşayan engelli çocukların psikoloji, psikiyatri ve nöroloji gibi rutin muayenelerine erişimlerinin \%60'a varan oranlarda azaldığı görülmüştür (70). İtalya'da yapılan bir çalışmada ise nörolojik rehabilitasyon gören çocukların \%90,6'sının kapanma döneminde rehabilitasyon hizmeti alamadığı ve \%67,7'sinin uzman randevusunun iptal edildiği rapor edilmiştir (71).

\section{SONUÇ}

Çocuklar COVID-19 pandemisinin dolaylı etkileri ile karşı karşıya kalan en savunmasız popülasyonlardan biri olmuştur. Sokağa çıkma kısıtlamaları, sağlık kurumlarındaki organizasyonel değişiklikler, ebeveynlerin COVID-19'a yakalanma korkusu, ulaşım güçlükleri, kişisel koruyucu ekipman eksikliği, finansal zorluklar ve okulların kapatılması çocukların her düzeyden sağlık hizmetlerine erişimini etkilemiştir. COVID-19'un çocuk sağlığı üzerindeki dolaylı etkilerinin en aza indirilmesi, çocuk mortalitesi ve mortalitesindeki istenmeyen sonuçları önlemek için önemli bir adım olacaktır. Hükümetler ve politika yapıcılar, sağlık hizmetlerine erişimi sürdürmek için gereken her türlü adımı atmalıdır. Sağlık kurumu yöneticileri, hastane organizasyonlarını sağlık hizmetlerine erişimdeki gecikmeleri önlemek ve yüksek kaliteli bakım sağlamaya devam etmeye yönelik olarak yeniden yapılandırmalıdır. Çocuk sağlığının geliştirilmesi ve korunmasında önemli görevleri olan çocuklarla çalışan hemşire ve hekim gibi sağlık profesyonelleri, pandeminin sağlık hizmetlerine erişim üzerindeki olumsuz etkilerini gidermek için güç ve rolleri kapsamında koruyucu, tedavi edici ve rehabilite edici hizmetlerini sürdürmeye devam etmelidir. Sağlık hizmetlerine erişim engeli olan çocuklara telesağlık ve gezici ekip hizmetleri ile gerekli müdahaleler yapılabilir. Ebeveynler sağlık hizmetlerine erişim eksikliği risklerinin COVID-19'dan çok daha kötü sonuçları olabileceğinin farkında olmalıdır.

Bilgilendirilmiş Onam: Katılımcılardan bilgilendirilmiş onam alınmıştır.

Hakem Değerlendirmesi: Dış bağımsız. 
Yazar Katkıları: Çalışma Konsepti/Tasarım- Z.A., Ö.Ö.Ş.; Veri ToplamaZ.A.; Veri Analizi/Yorumlama- Z.A., Ö.Ö.Ş.; Yazı Taslağı- Z.A.; İçeriğin Eleştirel İncelemesi- Z.A., Ö.Ö.Ş.; Son Onay ve Sorumluluk-Z.A., Ö.Ö.Ş.

Çıkar Çatışması: Yazarlar çıkar çatışması beyan etmemişlerdir.

Finansal Destek: Yazarlar finansal destek beyan etmemişlerdir.

Informed Consent: Written consent was obtained from the participants.

Peer Review: Externally peer-reviewed.

Author Contributions: Conception/Design of Study- Z.A., Ö.Ö.Ş.; Data Acquisition- Z.A.; Data Analysis/Interpretation- Z.A., Ö.Ö.Ş.; Drafting Manuscript- Z.A.; Critical Revision of Manuscript- Z.A., Ö.Ö.Ş.; Final Approval and Accountability- Z.A., Ö.Ö.Ş.

Conflict of Interest: Authors declared no conflict of interest.

Financial Disclosure: Authors declared no financial support.

\section{KAYNAKLAR/REFERENCES}

1. Qazi SH, Saleem A, Pirzada AN, Hamid LR, Dogar SA, Das JK. Challenges to delivering pediatric surgery services in the midst of COVID 19 crisis: experience from a tertiary care hospital of Pakistan. Pediatr Surg Int 2020;36(11):1267-73. doi:10.1007/ s00383-020-04721-0.

2. Silvagni D, Baggio L, Lo Tartaro Meragliotta P. Neonatal and pediatric emergency room visits in a tertiary center during the COVID-19 pandemic in Italy. Pediatr Rep 2021;13(2):168-76. doi:10.3390/pediatric13020023.

3. Taddei M, Bulgheroni S. Facing the real time challenges of the COVID-19 emergency for child neuropsychology service in Milan. Res Dev Disabil 2020;107:103786. doi:10.1016/j.ridd.2020.103786.

4. Poppe M, Aguiar B, Sousa R, Oom P. The impact of the COVID-19 pandemic on children's health in Portugal: The parental perspective. Acta Med Port 2021;34(5):355-61. doi:10.20344/amp.14805.

5. Wirrell EC, Grinspan ZM, Knupp KG, vd. Care delivery for children with epilepsy during the COVID-19 pandemic: An international survey of clinicians. J Child Neurol 2020;35(13):924-33. doi:10.1177/0883073820940189.

6. Bong $\mathrm{CL}$, Brasher C, Chikumba E, Mcdougall R, Mellin-Olsen J, Enright A. The COVID-19 pandemic: Effects on low- and middleincome countries. Anesth Analg Published online 2020:86-92. doi:10.1213/ANE.0000000000004846.

7. Dayal D, Gupta S, Raithatha D, Jayashree M. Missing during COVID-19 lockdown: Children with onset of type 1 diabetes. Acta Paediatr Int J Paediatr 2020;109(10):2144-6. doi:10.1111/apa.15443.

8. Zar HJ, Dawa J, Fischer GB, Castro-Rodriguez JA. Challenges of COVID-19 in children in low- and middle-income countries. Paediatr Respir Rev 2020;35:70-4. doi:10.1016/j.prrv.2020.06.016.

9. Menendez C, Gonzalez R, Donnay F, Leke RGF. Avoiding indirect effects of COVID-19 on maternal and child health. Lancet Glob Heal 2020;8(7):863-4. doi:10.1016/S2214-109X(20)30239-4.

10. Lazzerini M, Barbi E, Apicella A, Marchetti F, Cardinale F, Trobia G. Delayed access or provision of care in Italy resulting from fear of COVID-19. Lancet Child Adolesc Heal 2020;4(5):10-1. doi:10.1016/ S2352-4642(20)30108-5.
11. Chanchlani N, Buchanan F, Gill PJ. Addressing the indirect effects of COVID-19 on the health of children and young people. CMAJ 2020;192(32):921-7. doi:10.1503/cmaj.201008.

12. Roberton T, Carter ED, Chou VB, vd. Early estimates of the indirect effects of the COVID-19 pandemic on maternal and child mortality in low-income and middle-income countries: a modelling study. Lancet Glob Heal 2020;8(7):901-8. doi:10.1016/S2214109X(20)30229-1.

13. UNICEF. Maternal and newborn health and COVID-19. United Nations International Children's Emergency Fund. Published 2021. Son Erişim 1 Haziran 2021. https://data.unicef.org/topic/maternalhealth/covid-19/.

14. Balogun M, Banke-Thomas A, Sekoni A, vd. Challenges in access and satisfaction with reproductive, maternal, newborn and child health services in Nigeria during the COVID-19 pandemic: A crosssectional survey. PLoS One 2021;16(May):e0251382. doi:10.1371/ journal.pone.0251382.

15. Pant $S$, Koirala $S$, Subedi M. Access to maternal health services during COVID-19. Eur J Med Sci 2020;2(2):48-52. doi:10.46405/ ejms.v2i2.110.

16. Wu H, Sun $W$, Huang $X$, vd. Online antenatal care during the COVID-19 pandemic: Opportunities and challenges. J Med Internet Res 2020;22(7):e19916. doi:10.2196/19916.

17. Tanvir Ahmed, Ahmed Ehsanur Rahman, Taiwo Gboluwaga Amole, Hadiza Galadanci, Mushi Matjila, Priya Soma-Pillay, et al. The effect of COVID-19 on maternal newborn and child health ( $\mathrm{MNCH}$ ) services in Bangladesh, Nigeria and South Africa: call for a contextualised pandemic response in LMICs. Int J Equity Health 2021;20(1):1-6. doi:10.1186/s12939-021-01414-5.

18. Subhash Chandir, Danya Arif Siddiqi, Mariam Mehmood, Hamidreza Setayesh, Muhammad Siddique, Amna Mirza et al. Impact of COVID-19 pandemic response on uptake of routine immunizations in Sindh, Pakistan: An analysis of provincial electronic immunization registry data. Vaccine. 2020;38(45):714655. doi:10.1016/j.vaccine.2020.08.019

19. Jessica B., Joseph O, Alexander A, Lorna A, Musa S, Annettee N, et al.Indirect effects of COVID-19 on maternal, neonatal, child, sexual and reproductive health services in Kampala, Uganda. medRxiv. Published online 26 Nisan 2021:2021.04.23.21255940. doi:10.11 01/2021.04.23.21255940.

20. Buonsenso D, Cinicola B, Kallon MN, lodice F. Child healthcare and immunizations in Sub-Saharan Africa during the COVID-19 pandemic. Front Pediatr 2020;8:517. doi:10.3389/ fped.2020.00517.

21. Gildner TE, Thayer ZM. Birth plan alterations among American women in response to COVID-19. Heal Expect 2020;23(4):969-71. doi:10.1111/hex.13077.

22. Pires PN, MacaringueC, Abdirazak A, Mucufo J, Mupueleque M, Siemens $\mathrm{R}$, et al. Covid-19 pandemic impact on maternal and child dealth services access in Nampula, Mozambique: A mixed methods research. Res Sq. Published online 12 Kasım 2020:1-10. doi:10.21203/rs.3.rs-104405/v1.

23. Klein JD, Koletzko B, El-Shabrawi MH, Hadjipanayis A, Thacker $\mathrm{N}$, Bhutta Z. Promoting and supporting children's health and healthcare during COVID-19-International Paediatric Association Position Statement. Arch Dis Child 2020;105(7):620-4. doi:10.1136/ archdischild-2020-319370. 
24. Siedner JM., Kraemer JD, Meyer JM., Harling G, Mngomezulu T, Gabela P, et al. Access to primary healthcare during lockdown measures for COVID-19 in rural South Africa: An interrupted time series analysis. BMJ Open 2020;10(10):43763. doi:10.1136/ bmjopen-2020-043763.

25. Güler S, Topuz I, Ulusoy F. COVID-19 pandemisinde aile sağlığı merkezi çalışanlarının deneyimleri. Halk Sağlığı Hemşireliği Derg 2020;2(3):143-51.

26. Sidhu S, Abad-Vergara D. WHO and UNICEF warn of a decline in vaccinations during COVID-19. World Health Organization. Published 2020. Erişim 12 Mayıs 2021. https://www.who.int/ news/item/15-07-2020-who-and-unicef-warn-of-a-decline-invaccinations-during-covid-19.

27. Dinleyici EC, Borrow R, Safadi MAP, van Damme P, Munoz FM. Vaccines and routine immunization strategies during the COVID-19 pandemic. Hum Vaccines Immunother 2021;17(2):400-7. doi:10.1 080/21645515.2020.1804776.

28. World Health Organisation. At least 80 million children under one at risk of diseases such as diphtheria, measles and polio as COVID-19 disrupts routine vaccination efforts, warn Gavi, WHO and UNICEF. World Heal Organ 2020;(May):22-5.

29. Khan A, Bibi A, Sheraz Khan K, Butt AR, Alvi HA, Naqvil AD ET AL. Routine Pediatric Vaccination in Pakistan During COVID-19: How Can Healthcare Professionals Help? Front Pediatr 2020;8:613433. doi:10.3389/fped.2020.613433.

30. Nuzhath T, Ajayi KV, Fan Q, Hotez P, Colwell B, Callaghan T. Childhood immunization during the COVID-19 pandemic in Texas. Vaccine. 2021;39(25):3333-7. doi:10.1016/j.vaccine.2021.04.050

31. Fahriani M, Anwar S, Yufika A, Bakhtiar B, Wardani E, Winardi W etal. Disruption of childhood vaccination during the COVID-19 pandemic in Indonesia. Narra J 2021;1(1):1-11. doi:http://doi. org/10.52225/narraj.v1i1.7.

32. Piché-Renaud P-P, Ji C, Farrar MPH DS, vd. Impact of the COVID-19 pandemic on the provision of routine childhood immunizations in Ontario, Canada. medRxiv. Published online 14 Mayıs 2021:2021.05.11.21257048. doi:10.1101/2021.05.11.21257048

33. Zhong Y, Clapham HE, Aishworiya R, vd. Childhood vaccinations: Hidden impact of COVID-19 on children in Singapore. Vaccine 2021;39(5):780-5. doi:10.1016/j.vaccine.2020.12.054

34. Suk JE, Jimenez AP, Kourouma M, vd. Post-ebola measles outbreak in lola, Guinea, January-June 2015. Emerg Infect Dis. 2016;22(6):1106-8. doi:10.3201/eid2206.151652

35. WHO \& UNICEF. Immunization in the context of COVID-19 pandemic. World Heal Organ United Nations Child Fund. 2020;(April):1-6.

36. CDC. Interim guidance for routine and influenza immunization services during the COVID-19 pandemic. Centers for Disease Control and Prevention. Published 2020. Erişim Mayıs 12, 2021. https://www.cdc.gov/vaccines/pandemic-guidance/index.html

37. Marques de Miranda D, da Silva Athanasio B, Sena Oliveira AC, Simoes-e-Silva AC. How is COVID-19 pandemic impacting mental health of children and adolescents? Int J Disaster Risk Reduct 2020;51:101845. doi:10.1016/j.ijdrr.2020.101845

38. CDC. Children's Mental Health. Centers for Disease Control and Prevention. Published 2021. Erişim 9 Haziran 2021. https://www. cdc.gov/childrensmentalhealth/features/kf-childrens-mentalhealth-report.html.
39. UNESCO. UNESCO rallies international organizations, civil society and private sector partners in a broad Coalition to ensure \#LearningNeverStops. United Nations Educational, Scientific and Cultural Organization. Published 2020. Erişim 9 Haziran 2021. https://en.unesco.org/news/unesco-rallies-internationalorganizations-civil-society-and-private-sector-partners-broad.

40. Thakur A. Mental health in high school students at the time of COVID-19: A student's perspective. J Am Acad Child Adolesc Psychiatry 2020;59(12):1309-10. doi:10.1016/j.jaac.2020.08.005.

41. Leilei Liang, Hui Ren, Ruilin Cao, Yueyang Hu, Zeying Qin, Chuanen $\mathrm{Li}$, and Songli Mei. The effect of COVID-19 on youth mental health. Psychiatr Q 2020;91(3):841-52. doi:10.1007/s11126-020-09744-3.

42. Tang $S$, Xiang M, Cheung T, Xiang YT. Mental health and its correlates among children and adolescents during COVID-19 school closure: The importance of parent-child discussion. J Affect Disord 2021;279:353-60. doi:10.1016/j.jad.2020.10.016.

43. Singh S, Roy D, Sinha K, Parveen S, Sharma G, Joshi G. Impact of COVID-19 and lockdown on mental health of children and adolescents: A narrative review with recommendations. Psychiatry Res 2020;293:113429. doi:10.1016/j.psychres.2020.113429.

44. Zhou SJ, Zhang LG, Wang LL, Guo ZC, Wang JQ, Chen JC et al. Prevalence and socio-demographic correlates of psychological health problems in Chinese adolescents during the outbreak of COVID-19. Eur Child Adolesc Psychiatry 2020;29(6):749-58. doi:10.1007/s00787-020-01541-4.

45. Ciacchini B, Tonioli F, Marciano C, Faticato MG, Borali E, Pini A, et al. Reluctance to seek pediatric care during the COVID-19 pandemic and the risks of delayed diagnosis. Ital J Pediatr 2020;46(1):1-4. doi:10.1186/s13052-020-00849-w.

46. Raman R, Madhusudan M. Impact of the COVID-19 pandemic on admissions to the pediatric emergency department in a tertiary care hospital. Indian J Pediatr 2021;88(4):392. doi:10.1007/ s12098-020-03562-y

47. Nourazari S, Davis SR, Granovsky R, Austin R, Straff DJ, Joseph $J W$, et al. Decreased hospital admissions through emergency departments during the COVID-19 pandemic. Am J Emerg Med 2021;42:203-10. doi:10.1016/j.ajem.2020.11.029.

48. Isba R, Edge R, Auerbach M, Cicero MX, Jenner R, Setzer E, et al. COVID-19: Transatlantic declines in pediatric emergency admissions. Pediatr Emerg Care 2020;36(11):551-3. doi:10.1097/ PEC.0000000000002260.

49. Sharma S, Wong D, Schomberg J, Robins CK, Gibbs D, Berkowitz C, et al. COVID-19: Differences in sentinel injury and child abuse reporting during a pandemic. Child Abus Negl 2021;116:104990. doi:10.1016/j.chiabu.2021.104990.

50. World Health Organization. Addressing violence against children, women and older people during the COVID-19 pandemic: Key actions. World Health Organ 2020;(June):1-7.

51. Rosenthal CM, Thompson LA. Child abuse awareness month during the coronavirus disease 2019 pandemic. JAMA Pediatr 2020;174(8):812. doi:10.1001/jamapediatrics.2020.1459.

52. Raman $S$, Harries $M$, Nathawad R, Kayeremateng $R$, Seth $R$, Lonne $B$, et al. Where do we go from here? A child rights-based response to COVID-19. BMJ Paediatr Open 2020;4(1). doi:10.1136/ bmjpo-2020-000714.

53. Baron EJ, Goldstein EG, Wallace CT. Suffering in silence: How COVID- 19 school closures inhibit the reporting of child maltreatment. J Public Econ 2020;190:104258. doi:10.1016/j. jpubeco.2020.104258. 
54. McNally VV, Bernstein HH. The effect of the COVID-19 pandemic on childhood immunizations: Ways to strengthen routine vaccination. Pediatr Ann 2020;49(12):e516-22. doi:10.3928/1938235920201115-01.

55. Wimberly CE, Towry L, Caudill C, Johnston EE, Walsh KM. Impacts of COVID 19 on caregivers of childhood cancer survivors. Pediatr Blood Cancer 2021;68(4):e28943. doi:10.1002/pbc.28943.

56. Atout M, Tarawneh FS, Al-Kharabsheh A. Challenges faced by mothers caring for children with leukaemia during COVID-19 pandemic: A qualitative study. J Pediatr Nurs 2021;58:e74-e80. doi:10.1016/j.pedn.2021.01.009.

57. Elbarbary NS, dos Santos TJ, de Beaufort C, Agwu JC, Calliari LE, Scaramuzza AE. COVID-19 outbreak and pediatric diabetes: Perceptions of health care professionals worldwide. Pediatr Diabetes 2020;21(7):1083-92. doi:10.1111/pedi.13084.

58. Odeh R, Gharaibeh L, Daher A, Kussad S, Alassaf A. Caring for a child with type 1 diabetes during COVID-19 lockdown in a developing country: Challenges and parents' perspectives on the use of telemedicine. Diabetes Res Clin Prac 2020;168:108393. doi:10.1016/j.diabres.2020.108393.

59. Graetz D, Agulnik A, Ranadive R, Vedaraju Y, Chen Y, Chontada $G$, et al. Global effect of the COVID-19 pandemic on paediatric cancer care: a cross-sectional study. Lancet Child Adolesc Heal 2021;5(5):332-40. doi:10.1016/s2352-4642(21)00031-6.

60. Galloway DP, Mathis MS, Wilkinson LT, Venick RS, Wendel D, Cole CR, et al. Effect of the COVID-19 Pandemic on Pediatric Intestinal Failure Healthcare Delivery. J Parenter Enter Nutr 2021;45(1):50-6. doi:10.1002/jpen.2000.

61. Fisher JC, Tomita SS, Ginsburg HB, Gordon A, Walker D, Kuenzler KA. Increase in pediatric perforated appendicitis in the New York City metropolitan region at the epicenter of the COVID-19 outbreak. Ann Surg 2021;273(3):410-5. doi:10.1097/SLA.0000000000004426.

62. Ördek E, Demir M, Yağmur İ. Evaluation of the impact of COVID-19 pandemia on pediatric urological operations and the number of outpatient clinic patients in a province with, the highest birth rate Turkey. Pamukkale Med J 2021;14(3):632-7. doi:10.31362/ patd.895126.

63. Witt A, Ordóñez A, Martin A, Vitiello B, Fegert JM. Child and adolescent mental health service provision and research during the Covid-19 pandemic: Challenges, opportunities, and a call for submissions. Child Adolesc Psychiatry Ment Health 2020;14(1). doi:10.1186/s13034-020-00324-8.
64. Fegert JM, Vitiello B, Plener PL, Clemens V. Challenges and burden of the Coronavirus 2019 (COVID-19) pandemic for child and adolescent mental health: A narrative review to highlight clinical and research needs in the acute phase and the long return to normality. Child Adolesc Psychiatry Ment Health 2020;14(1):20. doi:10.1186/s13034-020-00329-3.

65. Racine N, Hartwick C, Collin-Vézina D, Madigan S. Telemental health for child trauma treatment during and post-COVID-19: Limitations and considerations. Child Abus Negl 2020;110:104698. doi:10.1016/j.chiabu.2020.104698.

66. Bulucu Büyüksoy GD, Özdil K, Çatiker A. Pandemisinde 6-12 yaş arası çocuklarda karşılanmamış sağlık hizmeti gereksinimleri. Halk Sağlığı Hemşireliği Derg 2021;3(1):4-17.

67. Young Minds. Coronavirus: Impact on young people with mental health needs Survey 2: Summer 2020. YoungMinds. Published 2020. Erişim 9 Haziran 2021. https://youngminds.org.uk/about-us/ media-centre/press-releases/coronavirus-having-major-impact-onyoung-people-with-mental-health-needs-new-survey/.

68. Swansburg R, Hai T, MacMaster FP, Lemay J-F. Impact of COVID-19 on lifestyle habits and mental health symptoms in children with attention-deficit/hyperactivity disorder in Canada. Paediatr Child Health 2021;2021:1-9. doi:10.1093/pch/pxab030.

69. Krasovsky T, Silberg T, Barak S, Eisenstein E, Erez N, Feldman I, et al. Transition to multidisciplinary pediatric telerehabilitation during the covid-19 pandemic: Strategy development and implementation. Int J Environ Res Public Health 2021;18(4):1-13. doi:10.3390/ijerph18041484.

70. Jeste S, Hyde C, Distefano C, Halladay A, Ray S, Porath M, et al. Changes in access to educational and healthcare services for individuals with intellectual and developmental disabilities during COVID-19 restrictions. J Intellect Disabil Res 2020;64(11):825-33. doi:10.1111/jir.12776.

71. Bova SM, Basso M, Bianchi MF, Savare L, Ferrara G, Mura E, et al. Impact of COVID-19 lockdown in children with neurological disorders in Italy. Disabil Health J 2021;14(2):101053. doi:10.1016/j.dhjo.2020.101053. 